\title{
Health and economic benefits of physical activity for patients with spinal cord injury
}

Larry E Miller'

William G Herbert ${ }^{1,2}$

'Miller Scientific Consulting, Inc., Asheville, NC, ${ }^{2}$ Department of Human Nutrition, Foods \& Exercise, Virginia Tech, Blacksburg, VA, USA
Correspondence: Larry E Miller Miller Scientific Consulting, Inc., 1854 Hendersonville Road, \#23I, Asheville, NC 28803, USA

$\mathrm{Tel}+\mathrm{I} 8284501895$

Email larry@millerscientific.com
This article was published in the following Dove Press journal:

ClinicoEconomics and Outcomes Research

3 October 2016

Number of times this article has been viewed

\begin{abstract}
Spinal cord injury (SCI) is a traumatic, life-disrupting event with an annual incidence of 17,000 cases in the US. SCI is characterized by progressive physical deconditioning due to limited mobility and lack of modalities to allow safe physical activity that may partially offset these deleterious physical changes. Approximately, $50 \%$ of patients with SCI report no leisuretime physical activity and 15\% report leisure-time physical activity below the threshold where meaningful health benefits could be realized. Collectively, about 363,000 patients with SCI, or $65 \%$ of the entire spinal cord injured population in the US, engages in insufficient physical activity and represents a target population that could derive considerable health benefits from even modest physical activity levels. Currently, the annual direct costs related to SCI exceed US\$45 billion in the US. Rehabilitation protocols and technologies aimed to improve functional mobility have potential to significantly reduce the risk of medical complications and cost associated with SCI. Patients who commence routine physical activity in the first post-injury year and experience typical motor function improvements would realize US\$290,000 to US\$435,000 in lifetime cost savings, primarily due to fewer hospitalizations and less reliance on assistive care. New assistive technologies that allow patients with SCI to safely engage in routine physical activity are desperately needed.
\end{abstract}

Keywords: ambulation, cost, exercise, exoskeleton, paraplegia, physical activity, spinal cord injury

\section{Introduction}

Spinal cord injury (SCI) is a traumatic, life-disrupting event with an annual incidence of 17,000 cases in the US. ${ }^{1}$ Despite concerted efforts to develop medical and surgical interventions intended to improve perioperative survival and minimize chronic neurological deficit associated with acute SCI, prognosis for full recovery is poor in most of the cases. In-hospital mortality rates following traumatic SCI range from $3 \%$ to $13 \%$, most commonly due to polytrauma. ${ }^{2}$ Further, less than $1 \%$ of patients experience complete neurological recovery by hospital discharge. ${ }^{3}$ Once patients complete acute rehabilitation and are discharged home, most will begin a chronic period of progressive physical deconditioning due to limited mobility and lack of modalities to allow safe physical activity that may partially offset these deleterious physical changes. This period is characterized by lifelong physical deterioration in the functioning of major body systems such that the life span of spinal cord-injured patients is 18 years shorter than age- and sex-matched healthy individuals. ${ }^{3,4}$ Further, these patients will endure severe long-term medical, functional, and psychological complications following the injury, thus increasing their risk for loss of employment or employability, decreasing 
quality of life, and resulting in tremendous societal cost. ${ }^{5,6}$ Overall, the clinical and economic burden of SCI is substantial and, given that the condition is currently irreversible, it will likely remain a major societal issue for decades to come.

\section{Chronic deconditioning in SCI patients}

Emerging therapies intended to reverse SCI and restore neural and motor pathways are on the horizon, although a definite cure remains elusive. Experimental studies have shown that stem cell injections may regrow glial cells and restore partial function in some patients, but exorbitant costs and inconsistent clinical benefit limit the utility of this therapy. ${ }^{7,8}$ Thus, except in rare cases, a patient will live with the physical, psychological, and economic burdens imposed by SCI for the remainder of life. SCI is responsible for a cascade of physiological decline, which collectively contributes to secondary complications, frequent hospitalizations, high cost, and shorter life expectancy. While SCI itself cannot be currently reversed, the associated physical deterioration may be partially offset by engaging in even modest levels of physical activity on a routine basis. However, for a variety of different reasons, exercise participation levels are extremely low in patients with SCI. ${ }^{9}$ Thus, from the time of injury through the remainder of life, the typical patient experiences declining physical health, reduced quality of life, and a significant financial burden. The reasons for the treatment gap for patients with SCI are several, including fear of causing additional bodily harm, inability to access exercise facilities, and lack of modalities to accommodate patient needs. There is a clear need to develop new and accessible technologies that may safely foster independent physical activity in spinal cord-injured patients.

\section{How many spinal cord-injured patients are affected by chronic deconditioning?}

The number of chronically sedentary patients with SCI has not been well characterized, but may be reasonably estimated from previous studies. The annual incidence of SCI is reported to be 54 per million. ${ }^{3}$ Given the current US population of 323 million and a median life expectancy of 32 years post-injury, the most recent estimate of SCI prevalence is 558,000 cases. ${ }^{1}$ Approximately, $50 \%$ of patients with SCI report no leisure-time physical activity and $15 \%$ report leisure-time physical activity below the threshold required for meaningful health benefits ( $<1$ hour/week). ${ }^{9}$ This suggests that there are approximately 279,000 completely sedentary patients with SCI in the US and 84,000 more patients who participate in leisure-time activities inadequate to positively impact health. Collectively, about 363,000 patients with SCI, or $65 \%$ of the entire spinal cord-injured population, engage in insufficient volumes of physical activity and represent a target population that could derive considerable health benefits from even modest activity levels.

\section{What is the duration of chronic deconditioning after $\mathbf{S C l}$ ?}

The median age at time of SCI is 30 years. ${ }^{3}$ While life expectancy following SCI is dependent on factors such as age, sex, cause of injury, and injury level, the median life expectancy following injury across all patients with SCI is 32 years, about 18 years less than age- and sex-matched nondisabled individuals. ${ }^{3,4}$ Annual mortality rates for those who survive the first post-injury year average $2.5 \%$ and increase as patients age. ${ }^{3}$ Therefore, unlike common chronic diseases that predominantly affect the elderly, such as coronary heart disease or chronic obstructive pulmonary disease, the typical SCI patient is faced with significant disability throughout the majority of their adult life.

\section{Physical consequences of SCl}

As individuals with SCI age, they experience the same chronic health risks that arise in the general population. The goals of an aging SCI patient remain largely the same as those of a nondisabled person - to maintain overall health, independence, and life satisfaction. However, aging with the additional challenge of a significant disability makes it exponentially more difficult for the SCI patient to maintain health status. At the time of injury, there is immediate and severe loss of sensory and motor function that triggers an extreme catabolic reaction due to loss of normal physiological stresses to tissue ${ }^{10}$ and neurohumoral responses. ${ }^{11}$ Protein degradation by-products lead to chronic increases in renal demand. Bones undergo extreme demineralization due to reduction or loss in muscle contraction forces. Spinal cord-injured patients have increased risks of osteoporosis, cardiovascular disease, respiratory problems, and muscular spasticity and contractures compared to the general population. ${ }^{12,13}$ Obesity risk increases in patients with SCI due to hypercaloric diet, lack of physical activity, and a reduction in metabolic rate, the latter a result of declines in fat-free mass and sympathetic nervous system activity. Severe immunosuppression leads to systemic inflammation and weakened immunity. ${ }^{14}$ Associated secondary complications such as fractures, falls, pressure ulcers, and systemic infections result in costly hospitalizations. 
Most secondary complications resulting from SCI are thought to be the direct result of immobility.

The typical SCI patient engages in only $40 \%$ of the activity levels of nondisabled peers. ${ }^{15}$ Given that the typical nondisabled adult is largely inactive highlights the extremely sedentary existence of patients with SCI. The percentage of patients with SCI able to walk at least 1 street block with or without assistive devices is only $32 \%$ at 1 year post-injury and declines as patients age, with $25 \%$ at 10 years and $15-20 \%$ between 20 and 30 years post-injury able to ambulate 1 block. Concomitantly, wheelchair dependence rises, from 59\% at 1 year, to $70 \%$ at 10 years post-injury, and between $75 \%$ and $80 \%$ thereafter. ${ }^{3}$ The combination of sedentary lifestyle combined with increased secondary complication risk exponentially increases the risk of expensive hospitalizations. In the year following SCI, $36 \%$ of patients will be hospitalized at least once and $13 \%$ will be hospitalized at least twice, with an average length of stay of 16 to 24 days per episode. ${ }^{3,16}$ Even beyond the first year of injury, $30 \%$ of patients will be hospitalized in any given year, with average stays of 22 days. ${ }^{3}$ Primary causes of hospitalization are genitourinary complications and, to a lesser extent, complications related to skin, respiratory, digestive, circulatory, and musculoskeletal diseases. ${ }^{3,16}$ Notably, pressure sores accounted for $7 \%$ of readmissions, but $28 \%$ of total bed-days, with a median length of stay per episode of 7 weeks. ${ }^{17}$

\section{Economic burden of SCI}

Starting at the time of initial injury, there is tremendous lifelong utilization of health care resources. The typical life span following SCI is 32 years, with considerable variation depending on the level of injury. ${ }^{18}$ Costs are highest during the first year following injury, but remain substantial each subsequent year. Average direct costs are US\$523,000 in the first year and US\$80,000 in each subsequent year, accounting for over US\$3 million in costs over a typical patient life span. ${ }^{19}$

In the first year after injury, private payers are responsible for the greatest percentage of SCI-related costs. Thereafter and throughout the typical post-injury life span of a spinal cord-injured patient, the Centers for Medicare \& Medicaid Services (CMS) pays the greatest portion of costs (Figure 1). Over the life span of a typical patient, the cumulative direct costs to primary payers will total US\$1.6 million for CMS, US\$1.1 million for private payers, and US\$400,000 for other payers (e.g. worker's compensation, Veteran's Administration) (Figure 2). Currently, the annual direct costs related to SCI exceed US\$45 billion annually in the US. Assuming that the incidence of SCI stays constant at 54 cases per million, median post-injury life expectancy remains 32 years, and given the US population projections, ${ }^{4}$ the cumulative direct costs to the health care system will exceed US\$1.4 trillion over the next 30 years, with CMS responsible for over US\$750 million (Figure 3). Moreover, given that the median survival rates following SCI have been increasing over time ${ }^{3}$ and with increasing health care costs, the costs of care for an SCI may be expected to increase beyond these conservative assumptions.

In addition to the direct costs of SCI, indirect costs related to lost wages, productivity, and fringe benefits are responsible for an additional burden of US\$72,000 per year. ${ }^{3}$ The health-related burden of disability due to SCI is among the

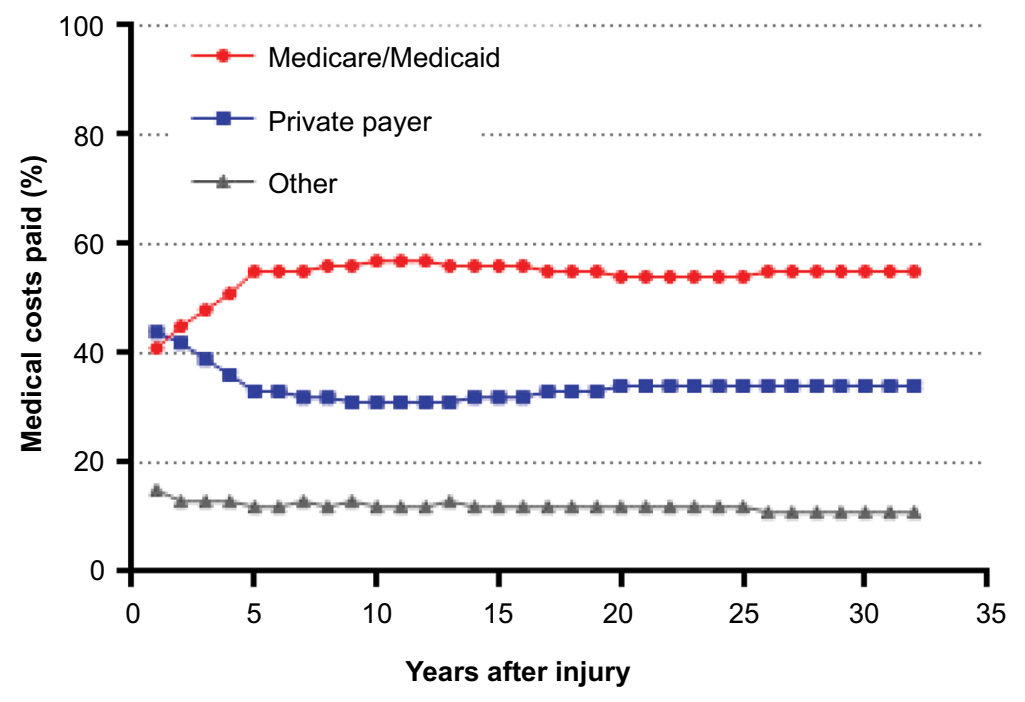

Figure I Percentage of lifetime medical costs by primary payer in a typical spinal cord-injured patient in the US

Notes: Model assumes 32-year survival after spinal cord injury. Medicare/Medicaid pays the majority of costs from year 2 and thereafter, plateauing at $\sim 55 \%$ of overall costs from year 5 and thereafter. 


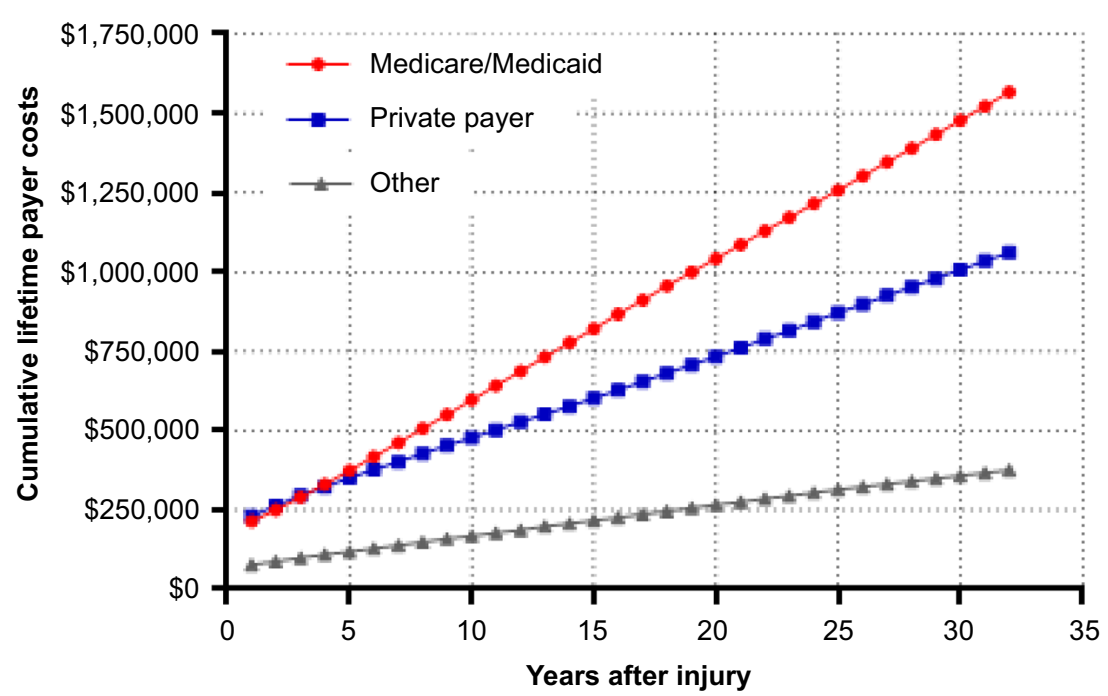

Figure 2 Cumulative lifetime primary payer costs in a typical spinal cord-injured patient in the US.

Notes: Model assumes 32-year survival after spinal cord injury. Over a typical post-injury life span, cumulative primary payer costs will total US $\$ 3.0$ million, with Medicare/ Medicaid paying US\$I.6 million (52\%), private payers paying US\$I.I million (35\%), and others (e.g. worker's compensation, Veteran's Administration) paying US $\$ 400,000$ (I3\%) of medical costs.

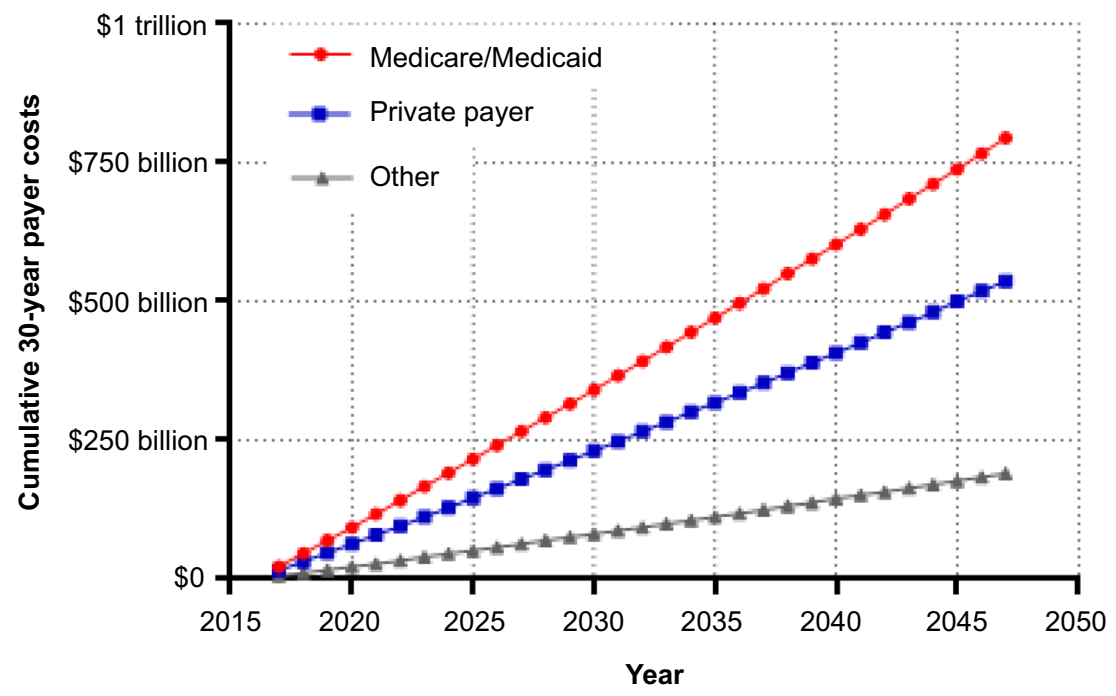

Figure 3 Cumulative 30-year primary payer costs for spinal cord-injured patients in the US.

Notes: Model assumes I,728 cases of spinal cord injury per I million population based on annual incidence of 54 per million, median post-injury life expectancy of 32 years, and US population projections. Over the next 30 years, cumulative medical costs will total US\$1.4 trillion, with Medicare/Medicaid paying US\$758 billion (53\%), private payers paying US $\$ 50$ I billion (35\%), and others (e.g. worker's compensation, Veteran's Administration) paying US\$I72 billion (I2\%) of medical costs.

highest of any known disease or disability. ${ }^{20}$ Prior to injury, $83 \%$ of individuals were employed whereas only $25 \%$ were employed at 4 years. ${ }^{18}$ When considering the lifetime direct costs of US\$3 million and US\$2.3 million in indirect costs, the total economic burden attributable to SCI is US\$5.3 million per patient.

\section{Health benefits of physical activity in spinal cord-injured patients}

Recovery of locomotion is one of the main priorities for spinal cord-injured patients. ${ }^{21,22}$ In addition to overcoming the obvious mobility and social issues related to the inability to stand or walk, regular ambulation may profoundly combat secondary medical problems associated with lack of weightbearing activity. ${ }^{23}$ There are a number of well-documented health benefits from even modest physical activity, such as improved lipid profile, lower diabetes risk, greater lean muscle mass, and greater quality of life. Physical activity at an intensity equivalent to a nondisabled person walking at 3 mph maintained for 1 hour per day, 3 days per week, is associated with preventive health benefits including cardiovascular and all-cause mortality risk reduction of $20 \%$ in the general 
adult population. ${ }^{23}$ For patients with SCI, those same health benefits should be a reasonable expectation. In addition, intermittent standing and habitual ambulation are known to improve upper body muscular fitness, ${ }^{24}$ slow decline in bone mineral by exposure to gravitational and muscular loading forces,${ }^{25}$ improve circulatory responses,${ }^{26}$ and reverse health risks associated with prolonged sitting. ${ }^{27}$

As with nondisabled individuals, the American College of Sports Medicine's ${ }^{28}$ exercise recommendations for patients with SCI include moderate-intensity exercise three to five times per week for 20 to 60 minutes per session. Appropriate modalities of cardiopulmonary exercise include arm crank ergometry, wheelchair propulsion, swimming, seated aerobics, functional electrical stimulation, and ambulation with assistive devices. Appropriately prescribed exercise programs are needed to improve health status and overall quality of life in patients with SCI. Although moderate physical activity is well tolerated by most patients, many patients are discouraged from participation due to incorrect perceptions about their functional capacity and exaggerated concern about causing harm. Many perceived barriers to participation in an exercise program have since been refuted, such as the notion of exercise leading to exacerbated contractures and increased risk of falling. ${ }^{29-31}$ The far greater risk to the spinal cord-injured patient is maintaining a chronically sedentary lifestyle, which leads to a progressive and predictable decline in physical deconditioning. At 1-year post-injury, $48 \%$ of patients with SCI are ambulatory, most with the assistance of a mobility aid. ${ }^{3}$ However, as patients age, the ability declines to $37 \%$ at 10 years, $26 \%$ at 20 years, and $22 \%$ at 30 years post-injury. ${ }^{3}$ Clearly, there is great need for novel modalities to maintain or improve ambulatory ability and to facilitate safe exercise at sufficient intensity known to elicit health benefits.

\section{Cost benefits of physical activity in spinal cord-injured patients}

Rehabilitation protocols and technologies aimed to improve functional mobility have potential to significantly reduce the risk of medical complications and cost associated with SCI. Following discharge from inpatient rehabilitation, physical activity levels dramatically decline ${ }^{32}$ such that the great majority of patients remain sedentary for the remainder of life. However, patients who are able to participate in physical activity enjoy tremendous health benefits and health care cost savings. Patients who exercise at least twice per week have a $50 \%$ lower risk of hospitalization in the first year versus sedentary patients. ${ }^{16}$ Furthermore, for every 5-point increase in Functional Independence Measure (FIM) motor score, the number of hospitalizations each year is reduced by 0.022 and percentage of patients requiring assistive care decreases by $3.6 \% .{ }^{33}$ Given that hospitalizations and assistive care represent almost $90 \%$ of the direct costs attributable to $\mathrm{SCI},{ }^{19}$ the potential cost benefits of improved motor function can be approximated.

For every 5-point increase in FIM motor score, annual direct costs decrease by about US $\$ 25,000$ in the first year and US $\$ 4,000$ annually thereafter. Based on previous studies of outpatient physical activity programs, FIM motor score improvements of 5 to 20 points can be reasonably expected with chronic exercise. ${ }^{34,35}$ Therefore, in a patient who commences routine physical activity in the first post-injury year and given a FIM motor score improvement of 10 to 15 points, cumulative direct cost savings would total US\$81,000 to US $\$ 122,000$ at 5 years and US $\$ 290,000$ to US $\$ 435,000$ over a lifetime, primarily due to fewer hospitalizations and less reliance on assistive care (Figure 4).

Further, it is reasonable to assume that mobility improvement may comparably reduce indirect costs. Riggins et al reported that patients who transitioned from walking at rehabilitation discharge to wheelchair use at 1 year had the lowest quality of life, whereas those who transitioned from wheelchair to walking reported the highest quality of life. ${ }^{36}$ Also, higher motor function 5 years after injury is associated with higher employment rates. ${ }^{37}$ Although no known data are available to accurately estimate the reduction in indirect costs due to improved functional ability, given that direct costs of SCI approximate the indirect costs, a parallel reduction in indirect costs over a patient's lifetime is plausible.

\section{Discussion}

Despite the fact that SCI affects only 1 in 18,000 people, ${ }^{1}$ this disability is responsible for a disproportionately excessive physical, psychological, and economic burden. Rehabilitative therapies intended to facilitate physical activity in patients with SCI suffer from poor adoption due to high expense, safety concerns, lack of availability, or inability to tailor exercise intensity to current fitness levels. This paper highlights a treatment gap for patients with SCI whereby new technologies that facilitate physical activity should be developed and incorporated into treatment protocols for patients with SCI. Availability of such modalities and given modest improvements in motor function ability has the potential to reduce the lifetime economic burden of SCI by $10-15 \%$. This is in stark contrast to the current paradigm whereby the typical SCI patient endures chronic deconditioning such that medical complications greatly exceed that of age-matched healthy individuals, life expectancy is greatly reduced, and 


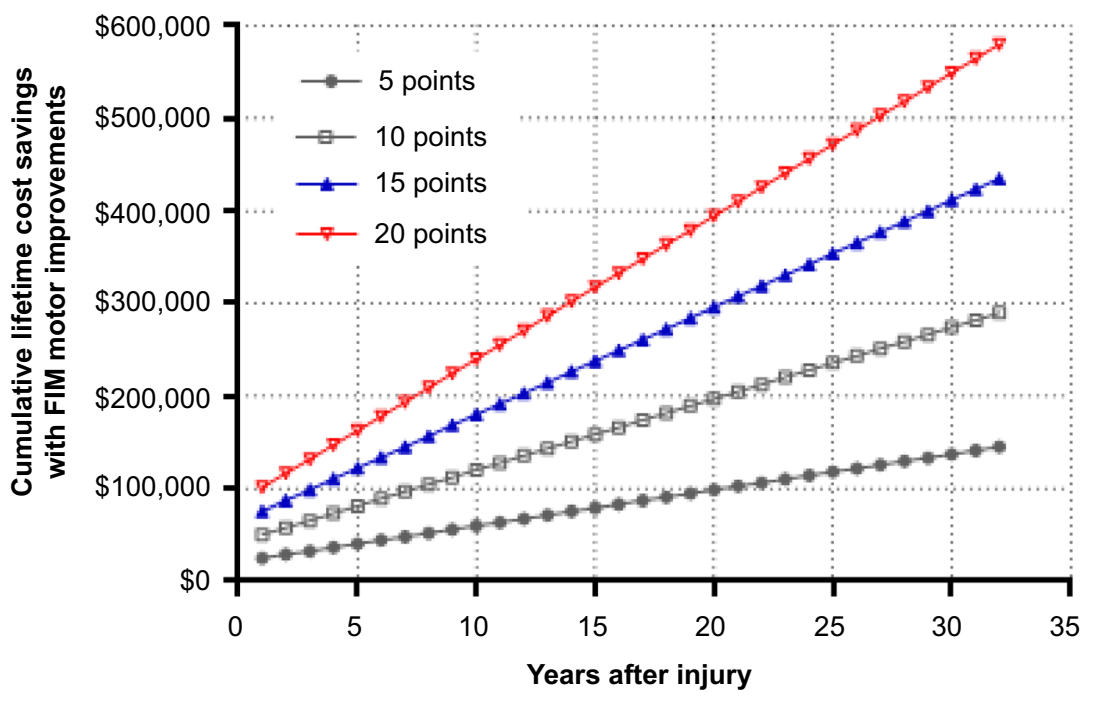

Figure 4 Cumulative lifetime cost savings with motor function improvements in a typical spinal cord-injured patient in the US.

Notes: Model assumes 32-year survival after spinal cord injury. Each line represents a different magnitude of improvement in FIM motor score due to chronic physical activity. Given typical improvements in FIM motor score (10- to I5-point increase), cumulative cost savings are US\$8I,000 to US $\$ 122,000$ at 5 years and US $\$ 290,000$ to US $\$ 435,000$ over a typical lifetime.

Abbreviation: FIM, Functional Independence Measure.

substantial economic resources are depleted, totaling over US $\$ 3$ million in direct costs over a lifetime.

Orthotic technologies such as hip-knee-ankle-foot orthoses and reciprocating gait orthoses have been employed with mixed success as a means of addressing this critical unmet health care need in the SCI population. The main limitation of these devices is a high metabolic demand such that most patients eventually discontinue use. ${ }^{38-41}$ Since the health benefits of physical activity are largely dependent on exercise frequency and duration, ${ }^{42}$ these traditional orthotic technologies likely have limited utility in ameliorating the chronic effects of inactivity due to SCI. Functional electric stimulation-assisted exercise is a treatment modality in which electrical impulses are applied to intact peripheral nerves supplying paralyzed muscles in order to produce functional movement and stimulate contractions of those muscles to promote recovery of motor function. Although improvements in cardiovascular function may be realized with routine use, these devices are primarily limited to arm cranking and cycle ergometry and do not facilitate weight-bearing ambulation. Despite the significant technical progress achieved in the last 10 to 15 years in this field, there is a general consensus that these systems are not sufficiently advanced and that they need further development. ${ }^{43,44}$ Powered exoskeletons are prescription devices composed of an external, powered, motorized orthosis that is placed over a person's paralyzed or weakened limbs for the purpose of facilitating standing, walking, climbing stairs, and performing activities of daily living. A recent meta-analysis concluded that powered exoskeletons allow patients with SCI to safely ambulate in real-world settings at a physical activity intensity conducive to prolonged use and known to yield health benefits. ${ }^{45}$ Specifically, the physiologic demand of exoskeleton-assisted ambulation was comparable to that of a nondisabled person walking at $3 \mathrm{mph}$. Further, $76 \%$ of patients were able to ambulate with no physical assistance. Improvements in bowel regularity and spasticity were reported in $61 \%$ and $38 \%$ of patients, respectively. Importantly, in this review, most patients presented with complete SCI. Generally, less than $5 \%$ of such patients have the ability to ambulate without physical assistance. The fact that $67 \%$ of patients in this review were able to engage in exoskeleton-assisted ambulation without physical assistance is very promising.

\section{Limitations}

There are several limitations of the methodology used in the current review. For simplicity, cost projections were predicted on assumptions applicable to a "typical" spinal cord-injured patient. This profile included median age of 30 years, median post-injury survival of 32 years, and averaged direct costs with no discount applied. Factors such as actual age of injury, neurological level of injury, sex, and baseline motor function scores will introduce variability when estimating costs for a single patient. Cost savings estimates with motor function improvement may be impacted by factors unrelated to physical activity, such as patient education and increased proficiency in activities of daily living. Additionally, we did not consider factors such as potential increases in longevity after SCI, increases in SCI incidence, or future increases in health care 
costs. To the extent that these factors might increase in the future, our cost projections may be underestimated. However, when considering all patients with SCI (as a group) within the population, we believe that the cost estimates are reasonable and should be considered as hypothesis generating and a basis to argue for more rigorous prospective studies.

\section{Conclusion}

$\mathrm{SCI}$ is responsible for significant lifelong loss of functional ability, frequent secondary complications, and tremendous costs to the health care system. Routine physical activity reduces the physical and economic burden of SCI. Therefore, widespread clinical adoption of new technologies that safely facilitate routine physical activity for patients with SCI in the home setting would result in significant cost savings.

\section{Disclosure}

This study was supported by ReWalk Robotics (Marlborough, MA, USA). The authors report no other conflicts of interest in this work.

\section{References}

1. Jain NB, Ayers GD, Peterson EN, et al. Traumatic spinal cord injury in the United States, 1993-2012. JAMA. 2015;313(22):2236-2243.

2. Chamberlain JD, Meier S, Mader L, von Groote PM, Brinkhof MW. Mortality and longevity after a spinal cord injury: systematic review and meta-analysis. Neuroepidemiology. 2015;44(3):182-198.

3. National Spinal Cord Injury Statistical Center. Spinal Cord Injury Model Systems: 2015 Annual Report. 2016. Available from: https://www.nscisc. uab.edu/reports.aspx. Accessed May 15, 2016.

4. U.S. Census Bureau. Projections of the Size and Composition of the U.S. Population: 2014 to 2060. 2015. Available from: https://www.census. gov/content/dam/Census/library/publications/2015/demo/p25-1143. pdf. Accessed May 25, 2016.

5. Cadotte DW, Fehlings MG. Spinal cord injury: a systematic review of current treatment options. Clin Orthop Relat Res. 2011;469(3): $732-741$

6. McKinley WO, Jackson AB, Cardenas DD, DeVivo MJ. Long-term medical complications after traumatic spinal cord injury: a regional model systems analysis. Arch Phys Med Rehabil. 1999;80(11):1402-1410.

7. Lu P, Kadoya K, Tuszynski MH. Axonal growth and connectivity from neural stem cell grafts in models of spinal cord injury. Curr Opin Neurobiol. 2014;27:103-109.

8. Reeves A, Keirstead HS. Stem cell based strategies for spinal cord injury repair. Adv Exp Med Biol. 2012;760:16-24.

9. Ginis KA, Latimer AE, Arbour-Nicitopoulos KP, et al. Leisure time physical activity in a population-based sample of people with spinal cord injury part I: demographic and injury-related correlates. Arch Phys Med Rehabil. 2010;91(5):722-728.

10. Dudley-Javoroski S, Shields RK. Muscle and bone plasticity after spinal cord injury: review of adaptations to disuse and to electrical muscle stimulation. J Rehabil Res Dev. 2008;45(2):283-296.

11. Fredrickson MD. Acute spinal cord injury management. $J$ Trauma. 2007;62(6 Suppl):S9.

12. Jensen MP, Truitt AR, Schomer KG, Yorkston KM, Baylor C, Molton IR. Frequency and age effects of secondary health conditions in individuals with spinal cord injury: a scoping review. Spinal Cord. 2013;51(12):882-892.
13. Sezer N, Akkus S, Ugurlu FG. Chronic complications of spinal cord injury. World J Orthop. 2015;6(1):24-33.

14. Eser P, Schiessl H, Willnecker J. Bone loss and steady state after spinal cord injury: a cross-sectional study using pQCT. J Musculoskelet Neuronal Interact. 2004;4(2):197-198.

15. van den Berg-Emons RJ, Bussmann JB, Stam HJ. Accelerometry-based activity spectrum in persons with chronic physical conditions. Arch Phys Med Rehabil. 2010;91(12):1856-1861.

16. DeJong G, Tian W, Hsieh CH, et al. Rehospitalization in the first year of traumatic spinal cord injury after discharge from medical rehabilitation. Arch Phys Med Rehabil. 2013;94(4 Suppl):S87-S97.

17. Middleton JW, Lim K, Taylor L, Soden R, Rutkowski S. Patterns of morbidity and rehospitalisation following spinal cord injury. Spinal Cord. 2004;42(6):359-367.

18. Krause JS, Edles P, Charlifue S. Changes in employment status and earnings after spinal cord injury: a pilot comparison from pre to post injury. Top Spinal Cord Inj Rehabil. 2011;16(4):74-79.

19. DeVivo MJ, Chen Y, Mennemeyer ST, Deutsch A. Costs of care following spinal cord injury. Top Spinal Cord Inj Rehabil. 2011;16(4):1-9.

20. Salomon JA, Haagsma JA, Davis A, et al. Disability weights for the Global Burden of Disease 2013 study. Lancet Glob Health. 2015;3(11):e712-e723.

21. Ditunno PL, Patrick M, Stineman M, Ditunno JF. Who wants to walk? Preferences for recovery after SCI: a longitudinal and cross-sectional study. Spinal Cord. 2008;46(7):500-506.

22. Lo C, Tran Y, Anderson K, Craig A, Middleton J. Functional priorities in persons with spinal cord injury: using discrete choice experiments to determine preferences. J Neurotrauma. Epub 2016 May 9.

23. Arem H, Moore SC, Patel A, et al. Leisure time physical activity and mortality: a detailed pooled analysis of the dose-response relationship. JAMA Intern Med. 2015;175(6):959-967.

24. Hicks AL, Martin Ginis KA, Pelletier CA, Ditor DS, Foulon B, Wolfe DL. The effects of exercise training on physical capacity, strength, body composition and functional performance among adults with spinal cord injury: a systematic review. Spinal Cord. 2011;49(11):1103-1127.

25. Astorino TA, Harness ET, Witzke KA. Effect of chronic activity-based therapy on bone mineral density and bone turnover in persons with spinal cord injury. Eur J Appl Physiol. 2013;113(12):3027-3037.

26. Milia R, Roberto S, Marongiu E, et al. Improvement in hemodynamic responses to metaboreflex activation after one year of training in spinal cord injured humans. Biomed Res Int. 2014;2014:893468.

27. Stamatakis E, Rogers K, Ding D, et al. All-cause mortality effects of replacing sedentary time with physical activity and sleeping using an isotemporal substitution model: a prospective study of 201,129 midaged and older adults. Int J Behav Nutr Phys Act. 2015;12:121.

28. Moore G, Larry Durstine J, Painter P. ACSM's Exercise Management for Persons With Chronic Diseases and Disabilities-4th Ed, By American College of Sports Medicine. Champaign, IL : Human Kinetics; 2016.

29. Turbanski S, Schmidtbleicher D. Effects of heavy resistance training on strength and power in upper extremities in wheelchair athletes. $J$ Strength Cond Res. 2010;24(1):8-16.

30. Jacobs PL. Effects of resistance and endurance training in persons with paraplegia. Med Sci Sports Exerc. 2009;41(5):992-997.

31. Jacobs PL, Nash MS. Exercise recommendations for individuals with spinal cord injury. Sports Med. 2004;34(11):727-751.

32. van den Berg-Emons RJ, Bussmann JB, Haisma JA, et al. A prospective study on physical activity levels after spinal cord injury during inpatient rehabilitation and the year after discharge. Arch Phys Med Rehabil. 2008;89(11):2094-2101.

33. Cohen JT, Marino RJ, Sacco P, Terrin N. Association between the functional independence measure following spinal cord injury and long-term outcomes. Spinal Cord. 2012;50(10):728-733.

34. Lugo LH, Salinas F, Garcia HI. Out-patient rehabilitation programme for spinal cord injured patients: evaluation of the results on motor FIM score. Disabil Rehabil. 2007;29(11-12):873-881.

35. Duran FS, Lugo L, Ramirez L, Eusse E. Effects of an exercise program on the rehabilitation of patients with spinal cord injury. Arch Phys Med Rehabil. 2001;82(10):1349-1354. 
36. Riggins MS, Kankipati P, Oyster ML, Cooper RA, Boninger ML. The relationship between quality of life and change in mobility 1 year postinjury in individuals with spinal cord injury. Arch Phys Med Rehabil. 2011;92(7):1027-1033.

37. Ferdiana A, Post MW, Hoekstra T, van der Woude LH, van der Klink JJ, Bultmann U. Employment trajectories after spinal cord injury: results from a 5-year prospective cohort study. Arch Phys Med Rehabil. 2014;95(11):2040-2046.

38. Bernardi M, Canale I, Castellano V, Di Filippo L, Felici F, Marchetti M. The efficiency of walking of paraplegic patients using a reciprocating gait orthosis. Paraplegia. 1995;33(7):409-415.

39. Scivoletto G, Petrelli A, Lucente LD, et al. One year follow up of spinal cord injury patients using a reciprocating gait orthosis: preliminary report. Spinal Cord. 2000;38(9):555-558.

40. Franceschini M, Baratta S, Zampolini M, Loria D, Lotta S. Reciprocating gait orthoses: a multicenter study of their use by spinal cord injured patients. Arch Phys Med Rehabil. 1997;78(6):582-586.
41. Sykes L, Edwards J, Powell ES, Ross ER. The reciprocating gait orthosis: long-term usage patterns. Arch Phys Med Rehabil. 1995;76(8): 779-783.

42. Foulds HJ, Bredin SS, Charlesworth SA, Ivey AC, Warburton DE. Exercise volume and intensity: a dose-response relationship with health benefits. Eur J Appl Physiol. 2014;114(8):1563-1571.

43. Ragnarsson KT. Functional electrical stimulation after spinal cord injury: current use, therapeutic effects and future directions. Spinal Cord. 2008;46(4):255-274.

44. Braz GP, Russold M, Davis GM. Functional electrical stimulation control of standing and stepping after spinal cord injury: a review of technical characteristics. Neuromodulation. 2009;12(3): 180-190.

45. Miller LE, Zimmermann AK, Herbert WG. Clinical effectiveness and safety of powered exoskeleton-assisted walking in patients with spinal cord injury: systematic review with meta-analysis. Med Devices (Auckl). 2016;9:455-466.
ClinicoEconomics and Outcomes Research

\section{Publish your work in this journal}

ClinicoEconomics and Outcomes Research is an international, peerreviewed open-access journal focusing on health technology assessment, pharmacoeconomics and outcomes research in the areas of diagnosis, medical devices, and clinical, surgical and pharmacological intervention. The economic impact of health policy and health systems
Submit your manuscript here: https://www.dovepress.com/clinicoeconomics-and-outcomes-research-journal

\section{Dovepress}

organization also constitute important areas of coverage. The manuscript management system is completely online and includes a very quick and fair peer-review system, which is all easy to use. Visit http://www.dovepress.com/testimonials.php to read real quotes from published authors. 